\title{
Três disParos em SARAJEVO: POESIA, FOTOGRAFIA E VIOLÊNCIA em Claudia Roquette-Pinto
}

Aulus MARTINS*

\section{RESUMO}

O objetivo deste ensaio é analisar as articulações entre a poesia e a fotografia. A concepção de que a fotografia estabelece uma relação de homologia com o referente é questionada por autores tais como Walter Benjamin, Roland Barthes, Susan Sontag, Giorgio Agamben e Arlindo Machado. É a partir dessa perspectiva que propomos uma leitura do poema "Em Sarajevo", de Claudia Roquette-Pinto, argumentando que a poeta incorpora no texto poético referências a imagens fotográficas com o propósito de evidenciar uma relação problemática entre a realidade e o que a fotografia capta.

PALAVRAS-ChAVE: poesia brasileira contemporânea, fotografia, violência, Claudia Roquette-Pinto

\section{INTRODUÇÃO}

Em um texto intitulado "A pequena margem de manobra de Claudia Roquette-Pinto", Luis Dolhnikoff faz uma crítica devastadora a "Em Sarajevo", como também a "Sítio", ambos de Margem de manobra (2005). Em linhas gerais, o argumento do crítico concentra-se em três pontos: "Em Sarajevo", afirma, é um típico poema contemporâneo, que mais parece ser um fragmento banal de prosa recortado aleatoriamente "e margeado à esquerda"; não passa de uma patética explicação ou comentário de imagens, e, por fim, é um poema oportunista, pois se refere de forma rasa a uma guerra de "grife", ou seja, uma guerra que recebeu imenso impacto da mídia, enquanto, no mesmo período, outros massacres foram ignorados pelos meios de comunicação. A conclusão

* Doutor em Letras pela Universidade Federal do Rio Grande do Sul (UFRGS), Porto Alegre, Rio Grande do Sul, Brasil.E-mail: aulus.mm@gmail.com. 
do crítico é a de que a poeta toma um assunto midiático e o trata de modo igualmente midiático (DOLHNIKOFF, 2009).

As questões apontadas pelo crítico são de fundamental importância para a compreensão da lírica contemporânea. Não sendo possível aprofundar todos os aspectos que constroem seu argumento, vamos nos deter apenas no segundo item da leitura de Dolhnikoff (a patética explicação ou comentário de imagens fotográficas), com uma pequena incursão ao terceiro aspecto, a questão ética aí implicada, a política das imagens e a forma ("rasa", de acordo com o crítico) como a violência é textualizada pelo poema.

\section{Em Sarajevo}

1.Na primeira foto ela ri,

2. selvagem,

3. e se mistura às amigas.

4. Um ano mais tarde,

5. posa com as mãos no colo,

6. coluna reta,

7. os pés cruzados pra trás.

8. Por dentro do uniforme pressente

9. uma mulher, a passos largos,

10. galgando as ruas de grandes cidades

11. - quem sabe no exterior.

12. Quando a vi, ali, distraída,

13. na escada do ônibus escolar,

14. nada me preparou para suas pernas abertas,

15. no meio a flor dilacerada

16. repetindo, entre as coxas,

17. o buraco da bala no peito:

18 um dois pontos insólito. (ROQUETTE-PINTO, 2005, p. 18)

\section{A FOTOGRAFIA E O DESCONCERTO DO REAL}

De fato, nos 18 versos desse poema, o eu lírico contempla fotos do conflito bélico de que Sarajevo foi palco. Uma vez que as fotos a que o eu lírico se refere não integram o volume em que o poema é publicado, o que temos é a "tradução" em linguagem verbal das fotografias, quer dizer, o leitor tem acesso tão somente à interpretação ou à leitura que o eu 
lírico realiza das fotos, ou, ainda, ao olhar que reorganiza os elementos visuais de uma cena já olhada e organizada anteriormente pelo fotógrafo. Portanto, muito mais do que uma mera descrição ou explicação dessas imagens, o eu lírico, na tematização do evento traumático, incorpora elementos da linguagem fotográfica, configurando, desse modo, um interessante entrecruzamento de poéticas visuais e verbais. É a partir desse espaço ambíguo, dessa sobreposição de olhares e linguagens que pretendemos analisar o poema "Em Sarajevo", destacando tanto os desdobramentos formais da articulação da poesia com a fotografia quanto seus aspectos éticos e políticos.

Ao lado da possibilidade de registrar o tempo passado, um dos usos culturais mais poderosos da fotografia, constituindo-se praticamente em um dogma do senso comum, é o registro fidedigno da realidade - não apena o registro de um evento em particular fixado pela foto, mas sobretudo a expressão última de uma verdade, a "prova definitiva" (KOSSOY, 2016, p. 21) daquilo que realmente aconteceu. Inúmeras práticas culturais sustentam a percepção do status de credibilidade da fotografia: o uso como fonte da historiografia, como prova jurídica, como prova de autenticidade na burocracia estatal (a identificação de pessoas pela foto que consta dos documentos oficias) etc.

Desde sua invenção, pois, a fotografia assombrou e seduziu por estabelecer (na expressão de Arlindo Machado) uma "homologia automática" (MACHADO, 2015, p. 39) entre a imagem e seu referente - perspectiva que pode ser localizada, dentre tantos outros exemplos, na teoria da "ontologia da fotografia" de André Bazin, em sua formulação do "complexo da múmia" (BAZIN, 1991). Trata-se, ainda segundo Machado, de uma visão "realista" que coincide com uma "concepção ingênua e largamente aceita por todos de que a fotografia fornece uma evidência: que ela 'reflete' alguma coisa que existe ou existiu fora dela e que não se confunde com o seu código particular de operação" (MACHADO, 2015, p. 39). Esse entendimento eminentemente realista, que configura uma visada "quase mística do fenômeno fotográfico" (MACHADO, 2015, p. 42) como expressão mimética do referente, é, no entanto, passível de ser contestado a partir da observação que entre o referencial e a imagem interpõe-se um aparelho ótico que, através de suas lentes que tanto refletem quanto refratam, aproximam ou afastam, atua ou intervém sobre o real. Isso posto, nada mais frágil 
do que o vínculo direto entre a imagem fotográfica e a verdade ou evidência referencial (FONTCUBERTA,2010); esse modo de encarar a fotografia, aliás, mais uma vez de acordo com Machado, reprime o poder da imagem de perturbar e desconcertar a realidade (MACHADO, 2015, p. 58).

As reflexões de Walter Benjamin, Roland Barthes, Susan Sontag e Giorgio Agamben acerca da fotografia confluem para a percepção de que a imagem fotográfica não é uma mera reprodução fiel da realidade, a mais realista - e, portanto, a que tem a "reputação pouco atraente de ser a mais fácil das artes miméticas" (SONTAG, 2004, p. 65) — como se supõe ser de acordo com o senso comum. Em seu ensaio "Pequena história da fotografia", publicado nos anos 30, Benjamin já assinala o caráter errático da técnica fotográfica, ao propor a noção de inconsciente ótico. Em vez de mostrar a realidade tal qual ela é ou supostamente seria, o filósofo alemão observa que a fotografia impele o observador a uma

necessidade irresistível de procurar nessa imagem a pequena centelha do acaso, do aqui e agora, com a qual a realidade chamuscou a imagem, de procurar o lugar imperceptível em que o futuro se aninha ainda hoje em minutos únicos, há muito extinto, e com tanta eloquência que podemos descobri-lo, olhando para trás (BENJAMIN,1985, p. 94).

Nesse sentido, a fotografia, através de seus recursos técnicos específicos, proporciona ao observador uma determinada experiência, que é a de vislumbrar aquilo que se oculta na realidade e que somente se torna perceptível ao olhar pela imagem fotográfica, objeto em que a “diferença entre técnica e magia" (BENJAMIN, 1985, p. 95) se neutraliza. Desse modo, da mesma forma que a psicanálise revela, por detrás das coisas banais e conhecidas, dos chistes e dos lapsos, um "inconsciente pulsional", a fotografia trabalha um "inconsciente ótico" (BENJAMIN, 1985, p. 94). A analogia entre a fotografia e a psicanálise aponta para a descontinuidade entre o conteúdo manifesto e o conteúdo latente que toda imagem comportaria. A fotografia revela (no sentido de descobrir algo oculto e também no sentido técnico da palavra, a ação de fixar a imagem, através de determinados agentes ou produtos químicos, no papel) a "pequena centelha do acaso", o "imperceptível" que escapa da 
percepção, nem tanto por sua "exatidão indexical" (BRIZUELA, 2014, p. 64), mas porque, ao operar um trabalho do inconsciente, permite o acesso a zonas obscuras que o olhar não consegue captar. Justamente por fixar e congelar um instante, a fotografia propicia a descoberta daqueles "momentos únicos" que fugiram à percepção, diante de um mundo, como dirá Benjamin em "O narrador", que não cessa de mudar, "exceto as nuvens, e debaixo delas, num campo de forças de torrentes e explosões, o frágil e minúsculo corpo humano" (BENJAMIN, 1985, p. 198). O inconsciente ótico revela, portanto, algum aspecto da realidade que, diante da fugacidade da vida, não pode ser plenamente apreendido. Graças, contudo, à descontinuidade do tempo, o passado que se torna presente na fotografia, criam-se as condições para que a atenção do olhar se concentre no detalhe antes desapercebido, mas agora revelado e dotado de nova e importante significação. Ao comentar uma distinção entre a imagem fotográfica e a cinematográfica ou televisiva, Susan Sontag destaca essa descontinuidade entre o tempo fixo e o tempo que flui:

Fotos podem ser mais memoráveis do que imagens em movimento porque são uma nítida fatia do tempo, e não um fluxo. A televisão é um fluxo de imagens pouco selecionadas, em que cada imagem cancela a precedente. Cada foto é um momento privilegiado, convertido em um objeto diminuto que as pessoas podem guardar e olhar outras vezes (SONTAG, 2004, p. 28).

A sugestão benjaminiana de inconsciente ótico pode ser aproximada da noção de punctum, proposta por Barthes em A câmara clara. Para o crítico francês, o punctum é uma espécie de efeito da fotografia sobre o observador, opondo-se a um outro aspecto ou princípio da imagem fotográfica, o studium. Enquanto este é, por assim dizer, o tema da fotografia, sua evidência mimética, que desperta no observador seu interesse ou apatia, o punctum, por sua vez, não é aquilo que o observador identifica na foto, mas aquilo que "parte da cena, como uma flecha” (BARTHES, 1984, p. 46), atingindo-o, ferindo-o. Barthes, aliás, explica a escolha dessa palavra para nomear esse princípio da imagem fotográfica, pois é a palavra latina para "essa ferida, essa picada, essa marca feita por um instrumento pontudo [...]; punctum é também picada, pequeno buraco, pequena mancha, pequeno corte — e também lance de 
dados" (1984, p. 46). É, pois, na articulação desses dois princípios, que Barthes entende a fotografia. Se o studium é o elemento que torna uma foto culturalmente interessante, da qual se gosta ou não, o punctum de uma foto é o que a eleva a uma outra dimensão de significado, é, em suma, "esse caso que, nela, me punge (mas também me mortifica, me fere)" (1984, p. 46, grifo do autor). Barthes chama a atenção para um paradoxo inerente ao punctum, que, sendo frequentemente um "detalhe" (1984, p. 69), tem uma "força de expansão", pela qual, "ao mesmo tempo que permanece um 'detalhe', preenche toda a fotografia" (1984, p. 73).

Desse modo, a dialética entre o studium e o punctum remete, a exemplo do inconsciente ótico de Benjamin, a uma descontinuidade entre aquilo que se vê (a dimensão mimética da imagem) e aquilo que transcende a referencialidade, o conteúdo latente da fotografia. Certamente que há fotos que poderão não apresentar um punctum, ou melhor, nem sempre o punctum será o mesmo de um observador a outro. Esse aspecto evidencia a natureza errática do punctum, uma vez que depende do "inconsciente ótico" de cada observador.

Em “O Dia do Juízo", ensaio incluído em Profanações, Giorgio Agamben identifica dois aspectos fundamentais da fotografia: o gesto e a exigência. Por gesto, o filósofo italiano entende a capacidade que tem a fotografia de recolher os vestígios da vida que estão sempre ameaçados de se perderem. Assim, uma foto restaura e salva da dispersão aqueles gestos banais e insignificantes que, de toda maneira, "resumem em si o sentido de toda uma existência" (AGAMBEN, 2007, p. 28). Dito por outras palavras, o instante capturado pela imagem fotográfica remete a uma "infinita recapitulação de uma existência" (2007, p. 28). Um outro aspecto ligado à fotografia é a exigência: "o sujeito fotografado exige algo de nós" (2007, p. 29). Trata-se, pois, de uma espécie de resistência do objeto ou pessoa retratada que "exigem não serem esquecidos" (2007, p. 29). Há certamente uma reminiscência benjaminiana nesses conceitos de gesto e de exigência, uma vez que apontam para a potência da imagem em iluminar, mesmo que de modo fugaz, o vivido. $O$ próprio argumento de Agamben, aliás, ao descrever o gesto, contém uma expressão de evidente dicção benjaminiana: "O poder do gesto de condensar e convocar ordens inteiras de potências angélicas constituise na objetiva fotográfica, e encontra na fotografia seu locus, sua hora tópica" (2007, p. 28, grifo do autor). 


\section{TrêS DisParos em SaRajevo}

O eu lírico contempla fotos de uma moça em três momentos ou situações distintas, em três momentos também distintos da organização do poema: primeira foto - versos 1 a 3; segunda foto - versos 4 a 11; terceira foto- versos 14 a 18 . Vale observar que, no último segmento do poema, o eu lírico abandona o vocabulário que remete à materialidade ou ao gestual implicados no ato fotográfico ("foto", "posa") e utiliza-se de uma estratégia que o coloca, por assim dizer, "dentro" da cena fotografada ("Quando a vi, ali"), ultrapassando, desse modo, a distância que se estabelecia anteriormente, quando observava cenas de cujo espaço não participava presencialmente. De qualquer forma, como veremos mais adiante, entendemos que o eu lírico ainda está diante de uma imagem fotográfica, e que esse recurso se constitui em uma interessante estratégia textual do poema que visa, justamente, potencializar um dos efeitos da fotografia sobre o espectador.

Entre as imagens fotográficas há um lapso, um corte temporal, explícito ("um ano mais tarde") ou sugerido ("Quando a vi”). Não há uma continuidade clara ou óbvia entre as cenas, mas o eu lírico, ao colocar essas imagens em sequência, estabelece uma determinada relação de continuidade, promovendo uma narratividade, ou seja, as fotos ou a imagem contam uma história, através do que mostram e ocultam - a história de uma moça que morava em Sarajevo e que foi morta, imagina-se, em virtude da guerra civil que devastou a cidade. Nesse contexto, é importante lembrar a noção de extraquadro. Sendo que "toda fotografia, seja qual for o referente que a motiva, é sempre um retângulo que recorta o visível" (MACHADO, 2015, p. 90), o extraquadro é tudo aquilo que ficou de fora do enquadramento escolhido ou obtido pelo fotógrafo, os fatos e as circunstâncias de que a fotografia é um pequeno recorte.

Evidentemente que o extraquadro atua sobre o quadro, a cena retratada, tanto que, em inúmeros casos, o fotógrafo, a fim de que esse aspecto se torne perceptível ao espectador, menciona-o no título ou na legenda da foto. O poema de Claudia Roquettte-Pinto parece utilizar-se de um recurso semelhante. As fotos descritas pelo eu lírico dependem desse extracampo, quer dizer, o conflito bélico, ausente nas primeiras duas imagens, e sugerido na última, é evocado pelo título do poema, a 
partir de sua contextualização histórica, título que apresenta um efeito de legenda e que não deve ser descartado. Assim, a questão do evento traumático, dramatizado explicitamente apenas na última foto, insinuase nas demais, em decorrência desse extraquadro atribuído pelo eu lírico, ressignificando imagens cujas cenas enquadradas não remetem, por si só, ao contexto da guerra. Desse modo, o título do poema tem um efeito de legenda para as fotos, que já não podem ser lidas desvinculadas de seus extraquadros: a guerra de Sarajevo.

A primeira foto é textualizada de forma sintética, em apenas três versos e 11 palavras, que captam um momento de radiante felicidade: a moça ri com as amigas. Essa foto parece ser um instantâneo, uma cena tomada de flagrante; contudo, conforme lembra Arlindo Machado, não há foto que não seja posada, no sentido de que todo registro pressupõe um determinado comportamento diante da câmara. O modo como o eu lírico descreve os elementos fotografados sugere, de fato, uma certa desorganização da cena (a moça misturava-se às demais amigas). No entanto, o olhar do eu lírico, seja seguindo o enquadre construído pelo fotógrafo, seja deslocando o olhar para outro ponto da foto, recorta essa imagem e destaca uma jovem dentre as demais. Além disso, é importante observar que, dentre as incontáveis imagens produzidas a partir do conflito em Sarajevo, o eu lírico seleciona apenas esta e outras duas, o que evidencia um processo de seleção, que, em última instância, configura-se em uma intervenção sobre o "real" que supostamente as fotografias registram.

O verso 2, composto por uma única palavra ("selvagem"), merece atenção. Aqui, "selvagem" é uma palavra investida de significados positivos, talvez algo como "ingenuidade" — a vida que é vivida de modo livre e feliz, curtindo o momento. "Selvagem" também pode significar aquele que não se deixa domesticar, quer dizer, um espírito isento das contingências impostas pelo mundo. No entanto, o significado mais profundo de "selvagem" parece se constituir, na estrutura do poema, em uma antecipação dos acontecimentos violentos pelos quais a cidade passará, a selvageria de que a jovem será vítima.

A espontaneidade selvagem captada na primeira foto contrasta com a imagem seguinte. Agora não mais a menina selvagem, livre, mas um corpo contido, controlado, domesticado. Repare-se que não se trata mais de um click espontâneo, mas de uma foto posada. Numa 
foto posada, ajusta-se o corpo, obedecem-se às ordens do fotógrafo etc. Todo o gestual da moça remete a uma postura de um corpo contido, controlado, submetido a uma determinada ordem, institucionalizada ou não: a "coluna reta", os "pés cruzados pra trás".

A palavra "uniforme" é importante nesse contexto. Uniforme é uma vestimenta que tem por função identificar o corpo, o indivíduo, determinada instituição, ou, antes, submetê-lo a certa ordem - aqui, escolar, como parece ficar claro no desenvolvimento do poema. $\mathrm{O}$ uniforme, como o nome indica, tende a neutralizar ou pasteurizar a singularidade do indivíduo. $\mathrm{O}$ uniforme indica que esse indivíduo pertence a um grupo. No entanto, algo daquela "selvageria" ainda pulsa dentro do uniforme: a "mulher, a passos largos". O que temos então é uma adolescente, uma colegial, que, apesar de pasteurizada junto às meninas nessa condição, tem uma potência a ser desenvolvida, amadurecida. Assim como a mulher é pressentida dentro do uniforme, o eu lírico também intui que essa liberdade indomesticada tem uma remota possibilidade de realização naquele contexto social - por isso que se sugere que a mulher apenas andará a passos largos no exterior, quer dizer, longe daquele contexto de guerra. Há aqui algo de tristemente irônico. Não se deve esquecer que a guerra da Bósnia era um conflito de limpeza étnica. Nesse sentido, o uniforme da moça pode identificá-la a determinado grupo étnico - assim como o uniforme militar, num conflito bélico, identifica um grupo e separa os "amigos" dos "inimigos". O desfecho do poema, ao colocar a moça entre as vítimas do conflito armado, evidencia que ela estava com o uniforme "errado", quer dizer, pertencia ao grupo dos inimigos que deveriam ser eliminados, pela ótica do lado oposto.

Conforme já se mencionou, essas duas fotos impactam não pelo que mostram, imagens mais ou menos convencionais, mais ou menos inocentes ou ingênuas, nas quais os conteúdos sugeridos pelo título do poema não aparecem, mas sobretudo pelo que ficou de fora do quadro, aquilo que ocultam. Nesse sentido, a terceira fotografia, a que mostra a moça morta na rua, é tanto mais forte pelo contraste com as imagens anteriores, as quais, como o eu lírico declara, não preparam o espectador (ou leitor) para o que virá. A ruptura, que essa terceira imagem provoca, obriga, justamente, a reordenar as imagens anteriores, a partir do contexto histórico que a legenda "em Sarajevo" determina. 
Desse modo, as fotografias cumprem, para retomar Agamben, a tarefa de reconstituição dos vestígios da vida que estão sempre ameaçados de se perderem. Trata-se, de fato, no caso da narrativa de que o poema dá conta, de uma vida que se perdeu em meio à brutalidade da guerra, da qual se mantém, entretanto, na captura de três momentos distintos, seu rastro, os gestos que resumem toda uma existência.

Por fim, na terceira fotografia, o desfecho do percurso da moça em Sarajevo, de jovem alegre à vítima de estupro promovido pelo genocídio. Como já se comentou, o eu lírico, ao descrever a cena da moça morta na escada do ônibus, não trata a imagem como uma fotografia, mas sugere que ele está ali, nas ruas da cidade destroçada pela guerra, na simultaneidade do fato. Esse recurso pode ser entendido como uma estratégia em que o eu lírico, diante dessa imagem tão impactante, assume, por assim dizer, o contracampo, ou seja, a posição do fotógrafo, apagando desse modo uma pressuposta passividade do espectador diante da imagem, uma vez que agora é ele quem recorta a cena, sem a intervenção do olhar do fotógrafo. Assim, ainda entendendo que o eu lírico está diante de uma foto, e não nas ruas da cidade diante de uma cena que acabou de acontecer, convém lembrar que o que se vê numa foto é o que foi visto anteriormente pelo fotógrafo. Esse fenômeno, que pode ser descrito como a sensação de sentir-se dentro de uma fotografia, é conhecido por "transferência de subjetividade":

Se toda imagem de natureza fotográfica já se encontra de alguma forma construída pela posição que o olho/sujeito ocupa em relação ao motivo, deve-se concluir que quem vê efetivamente a imagem não é o espectador: ele apenas endossa uma visão que foi realizada antes pela objetiva (MACHADO, 2015, p. 107)

Nesse sentido, ao transferir sua subjetividade para a cena fotografada, o eu lírico joga com a ilusão ótica de posicionar-se no contracampo do motivo, dando, pois, a impressão de que está lá, no meio da rua. Desse modo, sugere-se a quebra do distanciamento, seja temporal ou geográfico, que a fotografia impõe ao sujeito. Aqui, como se trata provavelmente de uma foto que circulava com o intuito de denunciar os atos de barbárie contra a população civil durante a Guerra da Bósnia, trata-se de um documento com peso de verdade, "a prova 
definitiva", a respeito dos eventos em Sarajevo. Nessa perspectiva, o olhar do eu lírico procura destacar a brutalidade da guerra fixando-se em uma de suas vítimas, brutalidade tanto mais comovente devido ao fato de a violência manifestar-se na vida dessa moça (e, por extensão, de todas as vítimas da guerra) não apenas na cena final, mas de alguma forma estar subjacente até mesmo nos momentos de radiante felicidade ou numa inocente sessão de fotografia para o álbum escolar.

Os versos finais do poema, ao alinhar o duplo ferimento, "a flor dilacerada entre as coxas" e o "buraco de bala no peito", concentra toda a violência da guerra nessa vítima cujo corpo sofre todas as consequências da barbárie, o estupro e o assassinato. $\mathrm{O}$ olhar que se fixa nesse "detalhe", as duas feridas visíveis, evoca, de alguma maneira, a noção barthesiana de punctum, aquilo que arrebata o espectador e provoca a ressignificação da foto para além de seu studium, que dizer, o seu referente imediato.

Para concluir, o que se tentou demonstrar com essa proposta de leitura é que o poema não apenas comenta e explica as imagens, mas confere a elas um sentido político e histórico. Não me parece que o poema faça um recorte midiático e espetacularizado do conflito bélico ou que o submeta à lógica da denúncia sensacionalista. Em vez disso, submete as imagens desse conflito a uma perspectiva que passa pela linguagem poética. As escolher fotos que não captam o referencial imediato da guerra, discute tanto a arbitrariedade que "escolhe" as vítimas quanto a que se abate sobre elas. Das três fotos escolhidas, apenas uma retrata diretamente o episódio traumático: uma clara opção pela não espetacularização do evento, evidenciando, ao contrário, uma espécie de conflito silencioso que somente é possível perceber relacionando essas imagens umas com as outras, conferindo-lhes um sentido de historicidade.

ThreE SHOtS IN SARAVEJO: POETRY, PHOTOGRAPHY AND VIOLENCE IN Claudia Roquette-Pinto

\section{Abstract}

This essay aims to analyse the links between poetry and photography. The conception that the photograph establishes a relation of homology with the referent is questioned by authors such as Walter Benjamin, Roland Barthes, 
Susan Sontag, Giorgio Agamben and Arlindo Machado. It is from this perspective that we propose a reading of the poem "Em Sarajevo" by Claudia Roquette-Pinto, arguing that the poet embodies in the poetic text references to photographic images with the purpose of highlighting a problematic relationship between the reality and what photography captures.

KEYwORDS: contemporary Brazilian poetry, photography, violence, Claudia Roquette-Pinto

TRES DISPAROS EN SARAJEVO: POESÍA, FOTOGRAFÍA Y VIOLENCIA EN Claudia Roquette-Pinto

RESUMEN

El propósito de este ensayo es analizar las articulaciones entre la poesía y la fotografía. La concepción de que la fotografía establece una relación de homología con el referente es cuestionada por autores como Walter Benjamin, RolandBarthes, SusanSontag, Giorgio Agamben y Arlindo Machado. Es desde esta perspectiva que proponemos una lectura del poema "Em Sarajevo" de Claudia Roquette-Pinto, argumentando que lapoetisaencarna en el texto poético las referencias a las imágenes fotográficas con el fin de destacar una relación problemática entre la realidad y la fotografíaque captura.

PALABRAS ClaVE: poesía brasileña contemporánea, fotografía, violencia, Claudia Roquette-Pinto

\section{REFERÊNCIAS}

AGAMBEN, Giorgio. O Dia do Juízo. Profanações. Tradução Selvino J. Assmann. São Paulo: Boitempo, 2007.

BARTHES, Roland. A câmara clara. Tradução Júlio Castañon Guimarães. Rio de Janeiro: Nova Fronteira, 1994.

BAZIN, André. Ontologia da imagem fotográfica. In: . O cinema: ensaios. Tradução Eloisa de Araújo Ribeiro. São Paulo: Brasiliense, 1991.

BENJAMIN, Walter. Passagens. Tradução Irene Aron \& Cleonice Paes Barreto Mourão. São Paulo: Imprensa Oficial; Belo Horizonte: Ed. UFMG, 2006.

. Pequena história da fotografia. In: Magia e técnica, arte e política: ensaios sobre literatura e história da cultura. Tradução Sergio Paulo Rouanet. São Paulo: Brasiliense, 1985. (Obras escolhidas, v.1). 
BRIZUELA, Natalia. Depois da fotografia: uma literatura fora de si. Tradução Carlos Nougué. Rio de Janeiro: Rocco, 2014.

DOLHNIKOFF, Luís. A pequena margem de manobra de Claudia RoquettePinto. Sibila: Revista de poesia e crítica literária, 15 set. 2009. Disponível em: <http://sibila.com.br/critica/a-pequena-margem-de-manobra-de-claudiaroquette-pinto/3135>. Acesso em: 10 de nov. 2017

FONTCUBERTA, Joan. $O$ beijo de Judas: fotografia e verdade. Tradução Maria Alzira Brum Lemos. Barcelona: Gustavo Gili, 2010.

KOSSOY, Boris. Realidade e ficções na trama fotográfica. São Paulo: Ateliê Editorial, 2016.

MACHADO, Arlindo. A ilusão especular. São Paulo: Gustavo Gili, 2015.

ROQUETTE-PINTO, Claudia. Margem de manobra. Rio de Janeiro: Aeroplano, 2005.

SONTAG, Susan. Sobre fotografia. Tradução Rubens Figueiredo. São Paulo: Companhia das Letras, 2004.

Submetido em 17 de novembro de 2017

Aceito em 6 de abril de 2018

Publicado em 31 de agosto de 2018 